\title{
PROLOGUE TO THE 2011 EDITION
}

There are three controversial questions in my treatment of the period running from 1730 to the 1840 s. For many analysts, perhaps the majority, this period represents the great turning point of the modern era, the moment when capitalism as a system, or modernity as a mode of existence, came into being. Readers of the first three volumes will know that I do not agree, since I think the great turning point was in the "long sixteenth century."

The second controversial question concerns the concept of "incorporation" into the capitalist world-economy of zones that were previously part of what I have been calling the "external arena." This assumes that a distinction can be made between the modern world-system (which is a capitalist worldeconomy) and other parts of the globe, especially in the period 1500-1750. It further assumes that there is a significant difference between being a zone outside the capitalist world-economy and being a peripheral zone within the capitalist world-economy.

A third issue is the concept of cyclical processes within the longue durée, and their role in explaining historical processes. These cyclical processes are what are called in French conjonctures (and cognate words in other Romance languages as well as Germanic and Slavic languages; the main exception to this usage is English, in which the word conjuncture is very much not a conjoncture). The principal economic cycle is what is often called Kondratieff long waves-a concept employed in this volume, but one whose very existence is often contested by others.

It is perhaps useful to restate the basic arguments for all three conceptsthe absence of a turning point in this period, the process of incorporation into the modern world-system, and the nature of the Kondratieff long waves. This is particularly important since I believe there has been considerable misunderstanding of what I have been trying to argue.

\section{The Great Turning Point}

Social scientists of all kinds like to designate turning points. It is a device that clarifies immensely the story they are trying to tell. It becomes a basic building block of their analyses of the immediate phenomena they are studying. The choice of turning points constitutes a basic framework within which we all operate. But choosing different turning points can change entirely the logic of the analyses. What are considered to be the "turning points" can mislead as readily as they can clarify.

If one reads the major works of the historical social sciences over the past two centuries, one will readily see that a strong favorite in the collective lit- 
erature for what is the major turning point in the past five hundred (or five thousand) years has been precisely the period 1730-1840s. Whether one is using the framework of "modernity" or "capitalism" or "industrialism" or "Western dominance of the world," most persons have dated its true onset to this period-or at least most persons until the last forty years or so, during which there has come to be a growing questioning of this period as the "great turning point." This entire work revolves around a rejection of this period as that turning point in favor of the "long sixteenth century" as the moment of the creation of the "modern world-system" as a "capitalist worldeconomy."

In a sense, the entire first three volumes make this case. But allow me to repeat the argument in condensed form. We have argued that the essential element of capitalism as a system is not, as is often contended, proletarian wage labor or production for the market or factory production. For one thing, all of these phenomena have long historical roots and can be found in many different kinds of systems. In my view, the key element that defines a capitalist system is that it is built on the drive for the endless accumulation of capital. This is not merely a cultural value but a structural requirement, meaning that there exist mechanisms within the system to reward in the middle run those who operate according to its logic and to punish (materially) those who insist on operating according to other logics.

We have argued that, in order to maintain such a system, several things are necessary. There has to be an axial division of labor, such that there are continuous exchanges of essential goods that are low-profit and highly competitive (i.e., peripheral) with high-profit and quasi-monopolized (i.e., corelike) products. In order to allow entrepreneurs to operate successfully in such a system, there needs in addition to be an interstate system composed of pseudosovereign states of differing degrees of efficacy (strength). And there also have to be cyclical mechanisms that permit the constant creation of new quasi-monopolistic profit-making enterprises. The consequence of this is that there is a quite slow but constant geographical relocation of the privileged centers of the system.

All of this did occur in the modern world-system, which was initially located primarily in most (but not all) of Europe and in parts of the Americas. It was, in Braudel's words, $a$ world and not the world. But by its internal logic, the capitalist world-economy expanded its boundaries as a system. It did this most spectacularly in the period treated in this volume, and we have tried to tell this story, describing which new regions this involved and why they came to be submitted to this expansion.

There are two forms of arguing against this position. One is to assert a process of gradual expansion in the globe of intercourse of various kinds (trade, communications, culture, conquest). This is seen as a multimillennial process, in which case neither the long sixteenth century nor the turn 
of the nineteenth century is so dramatic a moment as to constitute a turning point per se. Recent arguments about the long-standing centrality of China in the trade patterns of the Eurasian landmass are a variant on this argument. Capitalism as a concept largely drops out of the discussion when the issue is framed in this manner.

Or one can argue that the emergence of an industrial bourgeoisie and landless industrial workers, engaged in class conflict with each other, is the crucial defining characteristic, and that this appears only in this period and only in a few countries (perhaps only in England). That makes this period the "turning point." The interstate system and the existence of core-peripheral exchanges largely drop out of this discussion. This argument can be formulated either in "Marxist" language or in "Weberian" language. Either version essentially dismisses the notion of a world-system and its mode of constraining action.

\section{Incorporation into the World-System}

In volume 1, we distinguished between the external arena and the peripheral zones of the modern world-system. While parts of the external arena engaged in trade and other forms of interaction with the capitalist worldeconomy, the trade, we argued, was largely in "luxury" goods and was therefore not essential to the functioning of either party. As a result, the trade was relatively equal in the sense that each side was exchanging items that it considered of low value for items that it considered of high value. We might call this a win-win situation.

We suggested that peripheral products were traded with corelike products in a form of unequal exchange in which there was a complicated but real transfer of surplus value from the peripheral zones to the core zones. The exchanges were in essential goods, which each side needed to maintain itself. This trade could not be cut off without negative consequences for one or both sides. It was, however, possible for short periods to establish blockages to the free movement of goods, and we discussed the political circumstances in which such "protectionism" was practiced.

The cyclical processes within the capitalist world-economy led repeatedly to situations in which, in order to maintain the low production costs of peripheral goods, it was necessary to involve new regions within the worldeconomy-that is to say, to "incorporate" them within the division of labor.

Of course, the process of incorporation might receive resistance. It was argued, however, that the technological development of the capitalist worldeconomy, itself a process internal to that system, led over time to strengthening the military capacity of strong states of the world-economy compared with the military capacity of parts of the external arena. Hence, for example, whereas in the sixteenth century pan-European military strength was 
perhaps insufficient to "conquer" India, by the late eighteenth century this was no longer true.

Finally, how much expansion occurred at any given time was a function of how much new territory the capitalist world-economy was able to integrate at any given moment. It was also a function of how distant and therefore how difficult it was to incorporate manu militari certain regions. Hence, it is argued in this volume that whereas what we now call India was incorporated during this period, this was not true of China, which would be incorporated at a later time.

We then argued that incorporation was a process. It did not occur in a day or even a decade, but over a substantial period of time. However, we tried to show, by comparing four different regions-Russia, India, the Ottoman Empire, and West Africa-how "peripheralization" was a homogenizing process. That is, although these four zones were quite different from each other at the beginning of the process, the pressures of the world-system acted to make them more similar in their characteristics. For example, these pressures weakened the state structures in some zones and strengthened them in others, so that they would perform optimally in terms of the modalities of the modern world-system.

There have been two forms of arguing with this distinction. One has been to assert that the process of incorporation is a much more gradual one, with multiple stages. I am perfectly willing to entertain this amendment to the argument, the result of more empirical research into the matter.

The second has been to cast doubts on the distinction between luxury goods and essential goods. It has been asserted that what are often thought of as luxury goods are essential, at least as prestige items. It is further argued that the perspective on luxuries is culturally grounded and different peoples would define it differently.

I agree that this is a difficult distinction. But the fact that the concept of luxury is culturally grounded is part of my own argument. And although peacock feathers may seem essential to some groups, I find it difficult to accept that this is the same kind of necessity as the need of grains for human consumption. Furthermore, grains are bulk goods, and diamonds take up very little space in transportation. This seems to me to make a lot of practical difference.

So, I persist in feeling that the "equal" exchanges of two regions external to each other and the "unequal" exchanges within the capitalist world-economy constitute a crucial theoretical distinction. The capitalist world-economy is by its very mode of functioning a highly polarizing system. This is its most negative feature and, in the long run, one of its fatal flaws. Capitalism as a system is very different from the kinds of systems that existed before the long sixteenth century. It is not helpful analytically to lose this basic reality from view. 


\section{Kondratieff Cycles}

Kondratieff cycles are named after Nikolai Kondratieff, a Russian economist who described them in the $1920 \mathrm{~s}$. He was not in fact the first scholar to have described such cycles. And his descriptions of both how the cycles work and when they first occurred are no longer widely accepted. But the most widely used name for such cycles continues to be his. My own view of how they operate derives from my understanding of how producers in a capitalist system make profits from their enterprises and thereby are able to accumulate capital.

Capitalism is a system in which the endless accumulation of capital is the raison d'être. To accumulate capital, producers must obtain profits from their operations. However, truly significant profits are possible only if the producer can sell the product for considerably more than the cost of production. In a situation of perfect competition, it is absolutely impossible to make significant profit. Perfect competition is classically defined as a situation with three features-a multitude of sellers, a multitude of buyers, and universally available information about prices. If all three features were to prevail (which rarely occurs), any intelligent buyer will go from seller to seller until he finds one who will sell at a penny above the cost of production, if not indeed below the cost of production.

Obtaining significant profit requires a monopoly, or at least a quasimonopoly, of world-economic power. If there is a monopoly, the seller can demand any price, as long as he does not go beyond what the elasticity of demand permits. Any time the world-economy is expanding significantly, one will find that there are some "leading" products, which are relatively monopolized. It is from these products that great profits are made and large amounts of capital can be accumulated. The forward and backward linkages of these leading products are the basis of an overall expansion of the worldeconomy. We call this the A-phase of a Kondratieff cycle.

The problem for capitalists is that all monopolies are self-liquidating. This is because there exists a world market into which new producers can enter, however politically well defended a given monopoly is. Of course, entry is not easy and takes time. But sooner or later, others surmount the obstacles and are able to enter the market. As a result, the degree of competition increases. And when competition increases, prices go down, as the heralds of capitalism have always told us. However, at the same time, profits go down. When profits for the leading products go down sufficiently, the world-economy ceases to expand, and it enters into a period of stagnation. We call this the B-phase of a Kondratieff cycle. Empirically, the A- and B-phases together have tended to be fifty to sixty years in length, but the exact lengths have varied. Of course, after a certain time in a B-phase, new monopolies can be created and a new A-phase can begin. 
A- and B-phases of Kondratieff cycles seem, therefore, to be a necessary part of the capitalist process. It follows that they should logically be part of its operation from the very beginning of the existence of a capitalist worldeconomy. In the argument of this work, this means that they should be found from the long sixteenth century forward. And indeed, economic historians have regularly described such conjonctures during all this time, as can be seen in the many references to such descriptions in this and other volumes. To be sure, these economic historians did not call them Kondratieff cycles. But they may be found as a regular phenomenon in the system as a whole within the geographic boundaries we have been insisting were those of the capitalist world-economy in this period.

A few economic historians have described such cycles for the late Middle Ages in Europe, although this is a more contentious proposition. Were it to be established, it would give some support to those who wish to date the beginning of the modern world-system to an earlier date than the long sixteenth century. 